\title{
Formas em competição em construções condicionais na diacronia do português ${ }^{1}$ Maria Teresa Brocardo \\ Universidade NOVA de Lisboa, CLUNL
}

\begin{abstract}
:
In Portuguese past stages, both simple pluperfect (MPS) and conditional (COND) forms occurred in the apodosis of conditional constructions. In this study I investigate the 'competition' (cf., a.o., Berg, 2014), in the mentioned constructions, of these two verbal paradigms, in data retrieved from late $15^{\text {th }}$ to early $17^{\text {th }}$ century's textual sources. In most cases, the interpretation of the constructions contrasts: with MPS forms the constructions have a counterfactual reading, while constructions with COND forms are interpretable as hypothetical, thus evidencing the persistence, in modal uses, of the distinct tense values of these paradigms. Some 'critical' examples, however, appear to show that, in some contexts, the MPS is compatible with a noncounterfactual interpretation and also that the COND could have a counterfactual reading. I discuss the various conditioning factors which may have contributed to the convergence, and thus the competition, in conditional constructions, of the MPS and the COND, and the factors which may have determined the obsolescence of the modal uses of the MPS in the diachrony of Portuguese.
\end{abstract}

Keywords: conditional constructions, simple pluperfect, conditional, competing forms, diachrony

Palavras-chave: construções condicionais, mais-que-perfeito simples, condicional, formas em competição, diacronia

\section{Introdução}

Neste trabalho apresento dados da diacronia do português relativos a construções condicionais em que, em fases antigas da língua portuguesa, quer formas de condicional (doravante COND), quer formas de pretérito mais-que-perfeito simples (doravante MPS) ${ }^{2}$ ocorrem, na apódose.

O COND é caraterizado, no seu funcionamento temporal, por marcar um valor de posterioridade em relação a um tempo passado (e por isso é por alguns autores referido como «futuro do passado» ou «futuro do pretérito», cf. Cunha \& Cintra, 1984: 462), enquanto o MPS marca, temporalmente, também em relação a um passado, uma relação anafórica de anterioridade (sobre o funcionamento temporal destes paradigmas verbais, ver, por exemplo, Oliveira, 2013: 524; 527).

Numa perspetiva diacrónica, e no contexto geral românico, os dois paradigmas contrastam. O COND é uma inovação românica, sendo a sua emergência geralmente apontada como tendo decorrido da evolução de perífrases com o verbo latino habere ("ter, possuir"), com base no modelo que originou o futuro do presente: a partir de construções do tipo amare habet (amarINF + haverPRES) > amará, ter-se-á desenvolvido a correspondente perífrase, no passado, cantare habebat (amarINF +haverIMP), que passou a ser usada como um futuro do passado no discurso indireto (amaria). ${ }^{3}$ O MPS constitui, ao invés, um caso de assinalável

\footnotetext{
${ }^{1}$ Agradeço os comentários da/os revisora/as anónima/os.

${ }^{2}$ Além destas, uso ainda as seguintes abreviaturas para referir outros paradigmas verbais: Conj = conjuntivo; FUT = futuro; IMP = imperfeito; $\mathrm{INF}=$ infinitivo; $\mathrm{MPC}=$ mais-que-perfeito composto; $\mathrm{PP}=$ particípio passado; $\mathrm{PPS}=$ pretérito perfeito simples; $\mathrm{PRES}=$ presente .

${ }^{3}$ Sobre a discussão, na literatura, da relação entre o desenvolvimento dos 'novos' futuros das línguas românicas, futuro do presente e futuro do passado, ver, por exemplo, Parkinson (2009: 39-41). Salvi (2011: 331) parece mesmo sugerir alguma 'persistência' na emergência do COND, tendo em conta o facto de que a relação anafórica de posterioridade no passado era já em latim expressa por uma perífrase, com particípio futuro + IMP de esse "ser" (amaturus erat).
} 
conservação ou persistência, visto que corresponde a um paradigma verbal latino com continuidade, em termos formais, apenas em português e espanhol (ver, por exemplo, Salvi, 2011: 328; 330).

O facto de formas de ambos os paradigmas ocorrerem, em fases antigas da língua, em construções condicionais apontaria para algum tipo de convergência, num funcionamento caraterizável como modal, de que decorreria a hipotética competição que aqui se toma como objeto de estudo. $\mathrm{O}$ trabalho organiza-se do seguinte modo. Na secção 2 discuto brevemente a noção de competição em linguística histórica e refiro, de forma também breve, os fatores contextuais a que se associa a emergência de valores modais quer do COND quer do MPS. A secção 3 é dedicada à descrição dos dados. Começo por referir aas fontes usadas e a metodologia seguida (3.1) e descrevo e discuto depois os diferentes tipos de ocorrências levantados (3.2). Na secção 4 apresento as conclusões do estudo.

\section{Formas em competição}

A noção de 'competição' entre formas e / ou construções é usada em diferentes abordagens linguísticas, nomeadamente variacionistas e históricas, e tem, mais recentemente, sido objeto de propostas como a de Berg (2014), que lhe atribui um papel crucial no condicionamento e articulação de muitos fenómenos linguísticos de uso, estrutura, variação e mudança. Outros autores (De Smet et. al., 2018: 197) assumem uma visão mais crítica do conceito, sugerindo a necessidade de o precisar ou reformular. Estes autores referem-se sobretudo ao facto de que o termo 'competição', correspondendo, evidentemente, a uma metáfora, poderá não ser o mais adequado para explicar diferentes processos de mudança, em que interferem outros mecanismos e fatores, devendo a competição, portanto, ser aferida em função de um enquadramento mais preciso dos fenómenos em estudo.

Partirei aqui da definição, banal, de ‘formas em competição’ como unidades linguísticas formalmente distintas que (aparentemente) exprimem os mesmos valores, num mesmo contexto linguístico-discursivo, sendo assim (aparentemente) comutáveis. Na descrição de De Smet et. al., (2018: 197), «Functionally similar expressions are distinct forms that can be used more or less interchangeably in the same discourse contexts because their semantic extensions cover overlapping areas of conceptual space. Often, the relation between such expressions is described in terms of competition.». Em diacronia, a competição tenderá a resultar em substituição, com desuso ou obsolescência de uma das formas em competição (no uso e com o valor em causa), podendo, inversamente, ocorrer diferenciação, com as formas antes funcionalmente semelhantes a exprimirem valores distintos (ver, entre outros, De Smet et. al., 2018: 197). Sirvam de exemplo, para o português, a completa substituição de haver por ter como verbo principal de 'posse', no primeiro caso, e, no segundo, a diferenciação de valores das formas simples e composta do pretérito perfeito (ver, por exemplo, Brocardo, 2006; 2013; Mattos e Silva, 2002). Os autores citados referem ainda que a intervenção da analogia poderá determinar um resultado da competição diferente, a 'atração': «As a result of analogy, competing forms often show attraction, becoming functionally more (instead of less) alike» (De Smet et. al., 2018: 197).

A hipótese de competição entre COND e MPS, nos seus funcionamentos modais, parte da constatação de que a emergência deste tipo de valores para as formas destes paradigmas, a partir dos seus funcionamentos temporais, parece estar associada ou decorrer do mesmo tipo de fatores. Em fases antigas do português, ambos ocorrem na apódose (também na prótase no caso do MPS) ${ }^{4}$ de construções condicionais (explícitas ou implícitas), como se exemplifica em (1) e (2):

\footnotetext{
${ }^{4}$ Em latim, o MPS podia ocorrer apenas na apódose destas construções (cf. Pinkster, 1995: 301-302). Sobre o MPS modal, ver, e. o., Said Ali (1964': §1539), Mattos e Silva (1989: 428-432), Becker (2008), Brocardo (2010; 2012). Ver também Brocardo (2016), para uma breve descrição do COND em fases antigas do português.
} 
(1) E se alguu se querellar a torto do alcayde ena razõ aya a pea subredita que o alcayde aueria se iuygasse torto. [Foro Real, finais do século XIII, Ferreira, 1987]

(2) Ca se ele non confiara mais do homen santo don Onrado ca de si, non tirara a calça sua que tragia por religas e a posera sobelo corpo do morto [Diálogos de São Gregório, século XIV, Mattos e Silva, 1989]

Outros fatores, comuns também ao MPS e ao COND, que parecem ainda favorecer leituras modais destes paradigmas são a sua marcação em verbos de valor inerentemente modal (dever, poder), bem como a sua ocorrência em contextos de negação e interrogação, como se exemplifica em (3) a (7):

(3) E mais me praz da morte ca ueer eu a tua que oie nõ se podera escusar.

(4) Dise el Rei. como sabes tu que eu recebera morte [Livro de Linhagens do Conde D. Pedro, manuscrito da Ajuda, finais do século XIV, Brocardo, 2006b]

(5) Devera d'abastar por vimgamça dos pecados de nossos padres a perdição da casa de Çepta [Crónica do Conde D. Pedro de Meneses de Gomes Eanes de Zurara, finais século XV, Brocardo, 1997)

(6) ca por estas palauras se acabã todos os feytos de Deus ẽ todalas maneyras que o homẽ nõ poderia pẽssar nẽ dizer. [Primeyra Partida de Afonso X, Ferreira 1980]

(7) Mas quẽ poderia sẽ lastima ouvir o pramto que fazia Martym Lopez levamdo amte sy o corpo de seu irmão? [Crónica do Conde D. Pedro de Meneses de Gomes Eanes de Zurara, finais século XV, Brocardo, 1997]

Perante a identificação de fatores comuns aos dois paradigmas, na construção de valores modais, colocase a questão, para cuja resposta o presente trabalho pretende contribuir, de aferir se terá havido, efetivamente, competição entre COND e MPS. Além disso, dado que o MPS deixará de ocorrer, geralmente, com esses valores, sofrendo portanto obsolescência com um funcionamento modal, será também de procurar identificar os fatores que vieram a determinar o seu desuso em contextos como os acima exemplificados, ${ }^{5}$ e de que modo estes poderão estar relacionados com a hipotética competição entre os dois paradigmas.

\section{COND e MPS em construções condicionais na diacronia do português (testemunhos de finais do século XV a princípios do XVII)}

\subsection{Fontes e metodologia}

Os dados analisados neste trabalho correspondem a ocorrências de MPS e COND em construções condicionais, mas considerando apenas frases complexas com a oração subordinada condicional introduzida por se. Esta delimitação foi imposta pela heterogeneidade do tipo de pesquisas que seriam necessárias se se pretendessem incluir outras estruturas, formalmente muito diversas, o que, assumidamente, implica que será aqui tratado apenas um subconjunto dos dados relevantes, ainda que possivelmente o mais significativo, em termos quantitativos. ${ }^{6}$ De facto, várias outras estruturas ocorrem nos testemunhos que correspondem a construções com interpretação condicional, como, entre outras, com orações gerundivas, como se exemplifica em (8) e (9). Veja-se que em (9), por exemplo, semdo sabido como... é interpretável, no contexto em que a sequência ocorre, como 'se se tivesse sabido que...'.

\footnotetext{
${ }^{5}$ O MPS persiste em português contemporâneo em algumas expressões fixas do tipo quem me dera / tomara (cf., por exemplo, Oliveira, 2013: 525), aparentemente atestando essa preservação uma persistência marginal, como muitas vezes se observa em formas / construções que sofreram obsolescência.

${ }^{6}$ Não tenho, obviamente, dados precisos sobre esta quantificação, sendo a afirmação apenas baseada num conhecimento geral dos testemunhos.
} 
(8) e falamdo deste pecado nom nas dizemdo todas quamdo se comfessam, a comfissom nom seria uerdadeyra nẽ cõprida [Tratado de Confissom, século XV, Machado, 2003]

(9) elle teve tamta prudemçia $e$ fortalleza que sempre mostrou ser pessoa myseravell, porque, semdo sabido como elle hera esposado com ha filha do comde $e$ pessoa nobre, poseram seu rresgate em tamta vallia, que se nõ podera tam çedo tyrar [Crónica do Conde D. Pedro de Meneses de Gomes Eanes de Zurara, finais século XV, Brocardo, 1997]

Tendo também sido necessário delimitar as fontes usadas para o levantamento de dados, usei critérios que entreligam cronologia e género, além de, necessariamente também, questões de ordem prática, neste caso a acessibilidade dos testemunhos a partir de formatos pesquisáveis de modo (mais ou menos) automático. Selecionei assim um conjunto de testemunhos cujas datas vão de finais do século XV (último quartel), a princípios do XVII (primeiras décadas), que se enquadram em géneros como crónicas, relatos de viagens, hagiografia e ainda um 'tratado' de caráter religioso. Quer a delimitação cronológica quer a seleção de género decorreram de uma consideração, assente em pesquisas prévias, quanto à potencialidade / previsibilidade de ocorrência quantitativamente mais significativa do tipo de construções em estudo, em função da documentação remanescente disponível, que na época referida aumenta exponencialmente em termos quantitativos e de diversidade genológica, relativamente a épocas anteriores, sempre tendo em conta, necessariamente, que esta delimitação poderá sempre ser, como outras, discutível. Nas fontes pesquisadas tive em consideração a datação do testemunho usado, e não a datação suposta da redação original do 'texto', tendo também aqui procurado seguir um critério de seleção de testemunhos em que não há uma diferença muito significativa entre essas datas (atestadas ou conjeturais).

Elenco abaixo, por ordem cronológica, os testemunhos usados, com os dados relevantes, explicitando a sua datação ( $s d$. indica que o testemunho não está datado, sendo a datação conjetural), a forma de transmissão, manuscrita ou impressa (abreviadas $m s$. e impr.), bem como as siglas que uso nos exemplos. As referências completas das edições e recursos usados são dadas no final do artigo.

ZDM = Crónica do Conde D. Duarte de Meneses de Gomes Eanes de Zurara (ms. sd., último quartel do século XV)

$\mathrm{TC}=$ Tratato de Confissom (impr., 1489)

Vesp = Historia de Vespasiano (impr., 1496)

ZPM = Crónica do Conde D. Pedro de Meneses de Gomes Eanes de Zurara (ms. sd., finais do século $\mathrm{XV})$

$\mathrm{CRB}=$ Chronica dos Reis de Bisnaga (ms. sd., séc. XVI)

MSJ = Memorial da Infanta Santa Joana (ms. sd., post. a 1525)

GSC = História da Província de Santa Cruz de Pero de Magalhães Gândavo (impr., 1576)

PPer = Peregrinação de Fernão Mendes Pinto (impr., 1614)

SFBM = Vida de Frei Bartolomeu dos Mártires de Frei Luís de Sousa (impr., 1619)

\subsection{Descrição dos dados}

Começo com uma apresentação geral dos dados levantados, sintetizada no quadro 1. Na primeira coluna são identificados os testemunhos em que se atestam as construções em estudo, nas restantes apresentam-se os números de ocorrências, por testemunho, de cada uma das construções assinaladas: em (i) a construção com MPS na apódose e na prótase; em (ii) a construção com COND na apódose e IMPConj na prótase; (iii) inclui ocorrências de construções condicionais com distribuições diferentes de formas destes paradigmas, e ainda, entre parênteses retos, construções em que estes não ocorrem, mas que aqui incluí por permitirem evidenciar, nalguns casos, alternativas aos usos de formas de MPS e COND, em certos contextos. A indicação '?' assinala 
formas ambíguas, nomeadamente por razões que se prendem com as suas grafias, quanto ao paradigma verbal em que se enquadrarão.

\begin{tabular}{|c|c|c|c|}
\hline $\begin{array}{l}\text { Testemunhos } \\
n^{0} \text { palavras }\end{array}$ & $\begin{array}{l}\text { (i) } \\
\text { MPS } \\
\text { se MPS + MPS }\end{array}$ & $\begin{array}{l}\text { (ii) } \\
\text { COND } \\
\text { se IMPConj + COND }\end{array}$ & $\begin{array}{l}\text { (iii) } \\
\text { Outras ocorrências } \\
\text { [sem MPS ou COND] }\end{array}$ \\
\hline 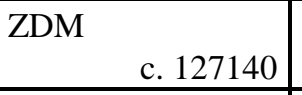 & 37 & 17 & \\
\hline \begin{tabular}{ll|} 
TC & \\
& 27598 \\
\end{tabular} & 6 & 9 & $\begin{array}{l}1 \text { se FUTConj + COND } \\
{[1 \text { se IMPConj + auer IMP }} \\
d e+\text { INF }] \\
{[1 \text { se IMPConj + PRES }]}\end{array}$ \\
\hline c. 19600 & 2 & & $\begin{array}{l}2 \text { se MPS + IMP } \\
{[1 \text { se IMPConj + FUT] }}\end{array}$ \\
\hline 134699 & 46 & 24 & $\begin{array}{l}1 \text { se MPS + COND } \\
1 \text { se IMPConj + MPS? / } \\
\text { FUT? } \\
1 \text { se } \text { PRES + COND } \\
2 \text { se MPCConj + COND } \\
{[3 \text { se IMPConj + IMP] }} \\
{[1 \text { se IMPConj + FUT] }} \\
{[1 \text { se IMPConj + PRES] }}\end{array}$ \\
\hline 43833 & 2 & 1 & \\
\hline c. 52000 & & 1 & \\
\hline 22944 & 4 & 1 & \\
\hline 49683 & 3 & 1 & 1 se MPS + PRES? \\
\hline 43833 & 5 & & \\
\hline c. 521330 & 105 & 54 & \\
\hline
\end{tabular}

Quadro 1: Apresentação geral dos dados levantados

Começo por notar que não interpreto os dados quantitativos como estando, pelo menos direta e linearmente, relacionados com 'frequência'. A quantificação de ocorrências num corpus não poderá nunca ser interpretada de modo absoluto, dado não só o caráter parcial desse corpus relativamente à documentação de uma dada época, mas também ao caráter remanescente dessa documentação, além de outras questões associadas, por exemplo, às formas de transmissão dos textos cujos testemunhos são explorados (testemunhos únicos ou múltiplos, cópia manuscrita ou impressa, etc.). Tomar-se-ão, portanto, as referências que faço à quantificação como apenas apontando tendências ou pistas a explorar na investigação. 
No que respeita às ocorrências, em termos absolutos, nos dados levantados, pode constatar-se um aparente predomínio, à partida, do MPS (105) sobre o COND (54) na apódose das construções condicionais aqui estudadas. Um outro aspeto a notar como relevante para a marcação de valores genericamente caraterizáveis como modais de ambos os paradigmas (como já notado na secção 2) é a sua incidência em verbos de valor inerentemente modal, e também em contextos de negação (neste caso na apódose, na prótase ou em ambas) como se esquematiza no quadro 2.

\begin{tabular}{|c|c|c|c|c|c|c|}
\hline \multirow{3}{*}{ negação } & \multicolumn{3}{|c|}{$\begin{array}{l}\text { Construções com MPS } \\
(105)\end{array}$} & \multicolumn{3}{|c|}{$\begin{array}{l}\text { Construções com COND } \\
(54)\end{array}$} \\
\hline & $\begin{array}{l}\text { prótase } \\
44\end{array}$ & $\begin{array}{l}\text { apódose } \\
13\end{array}$ & $\begin{array}{l}\text { ambas } \\
10\end{array}$ & $\begin{array}{l}\text { prótase } \\
6\end{array}$ & $\begin{array}{l}\text { apódose } \\
11\end{array}$ & $\begin{array}{l}\text { ambas } \\
5\end{array}$ \\
\hline & \multicolumn{3}{|c|}{67} & \multicolumn{3}{|c|}{22} \\
\hline \multirow[t]{2}{*}{ modais } & \multicolumn{3}{|c|}{$\begin{array}{c}\text { deuer } 6 \\
\text { poder } 15\end{array}$} & \multicolumn{3}{|c|}{ poder 8} \\
\hline & \multicolumn{3}{|c|}{21} & \multicolumn{3}{|c|}{8} \\
\hline
\end{tabular}

Quadro 2: Incidência em contextos de negação e modais

Ainda que as diferenças em termos proporcionais (face ao número total de ocorrências de formas de cada paradigma) não sejam marcadamente diferentes para o MPS e o COND, pode observar-se que o primeiro apresenta uma larga predominância de ocorrências neste tipo de contextos (quase 84\%), ainda assim maioritários face ao total de ocorrências no caso do COND $(56 \%)$, o que poderia levar a pensar que a marcação de valores modais no MPS estaria mais dependente de fatores contextuais.

$\mathrm{Na}$ larga maioria das atestações analisadas, ${ }^{7}$ as construções condicionais com MPS e COND contrastam na sua interpretação, que é contrafactual no caso do primeiro e hipotética no caso do segundo, como se exemplifica em (26) e (46) em contraste com (130) e (144):

(26) Fernã Lopez contador delRey foy em aquelle dya chegado ao derradeyro perigoo onde acabara se lhe Pedro Borges nõ acorrera. [ZDM]

(46) te direi o porque mandei matar esse mouro que trouxeste contigo , porque se fora português, ou cristão, eu te juro em minha lei que o não fizera. [PPer]

(130) nenhuũ nõ deue tomar o que seu nom he. Ca se nẽhuũ nõ tomase o perdido ueria seu dono e achaloya. [TC]

(144) se estes aquy vivessem, nos nunca aquy poderiamos criar cabra, nẽ porco, nẽ outra animallia. $[\mathrm{ZPM}]^{8}$

Este tipo de exemplos indiciam, assim, uma não convergência nos valores marcados, pelo MPS e COND, nestas construções. Quando ocorre MPS, a leitura gerada é a de que a situação não ocorreu, num tempo passado (porque não se verificou a condição), mas com o COND marca-se a possibilidade de ocorrência da situação descrita, em função da possibilidade de atualização da condição, num tempo futuro. Teremos aqui, portanto, a interferência de valores temporais associados aos dois paradigmas, ou seja, do valor

\footnotetext{
${ }^{7}$ Nesta secção, a numeração dos exemplos não é contínua, correspondendo antes à ordenação e organização da totalidade das atestações levantadas.

${ }^{8}$ Note-se que neste exemplo o contexto alargado da sequência textual permite afirmar a interpretação hipotética, visto que o emissor (o conde D. Pedro) está a argumentar sobre a estratégia de defesa da cidade de Ceuta, pouco depois da tomada da cidade, portanto antecipando a hipótese de 'eles [os mouros] aqui [perto da cidade] viverem', caso não sejam afastados por ações não apenas de defesa, mas de ataque, como aqui defende.
} 
de anterioridade, no caso do MPS, e de posterioridade, no caso do COND. ${ }^{9}$ Os dois paradigmas 'competem' apenas no sentido em que ocorrem no mesmo tipo de construção sintática, mas a sua interpretação é diferenciada.

Assinalei, porém, várias atestações em que não é igualmente patente esta diferenciação dos valores marcados pelas formas dos dois paradigmas. Nestes casos, a interpretação parece resultar algo ambígua e esbater-se a oposição entre a interpretação contrafactual do MPS e hipotética do COND, o que apontaria assim para uma potencial competição entre os dois. Assinalei 6 destes exemplos, que aqui referirei como 'críticos' ${ }^{10}$ nas ocorrências de MPS, e 4 nas de COND.

Começo por apresentar exemplos de MPS:

(40) Pequey pelo coraçõ ẽ cuydando muytas maas cuydações e maos pensamẽtos cõsẽtĩdo a eles e nõ lhes cõtradizẽdo como deuera e podera se quisera. [TC]

(45) fez estes três feitos muito notáveis, de que os seus todos ficaram tão animados, e com tamanha ousadia, que quiseram logo naquela noite cometer a cidade, se o rei para isso lhes dera licença, mas por ser o escuro grande, e a gente estar muito cansada, se contentou com que tinha feito. [PPer]

(32) quisera fazer hũa grande cousa se o nom empachara grande doẽça que sobreueo aa condessa sua molher. [ZDM]

(72) E com toda a festa da voda, Rruy Gomez quisera deyxar o taimbo $e$ ser o primeiro que sahyra da ygreja, se lho o comde quisera cõsẽtyr. [ZPM]

Nos exemplos acima, (40), (45), (32) e (72), a ambiguidade estará associada a diferentes interpretações de deuer (deôntico), em (40), e de querer, este marcando, eventualmente de forma ambígua, volição ou intenção. Veja-se que, contrastivamente com, por exemplo, (26), em que a leitura de acabara (no contexto parafraseável por 'morrerra') é negativa, isto é, a situação não ocorreu, porque não ocorreu a condição ('não acorrer'), já em (40), sendo também a condição - se quisera - interpretável como negativa ('não quis'), essa leitura não parece clara para deuera, dado justamente o seu valor modal deôntico, que não é aqui negado. Também nos outros exemplos a ocorrência na apódose de querer, a que se associam intrinsecamente valores modais (volição, intenção), gera incompatibilidade com uma interpretação negativa.

No caso de ocorrências do COND, há atestações em que parecem gerar-se leituras contractuais, ou pelo menos ambíguas:

(118) E elle aficado de seus requerimẽtos, fĩ cou o conto da lãça no chaão e ẽcostãdosse a ella disse callaaeuos ca se me conhecessees nõ fallaryees assy. [ZDM]

(119) se aas cousas quisessees guardar toda sua ordem acharyees que nõ era bẽ meterdes ẽ auẽtura quãta honra elRey nosso Senhor com uosco tẽ guaanhada na filhada e defensom desta uilla. [ZDM]

(122) dam tal uyda aaquelles que teẽ catiuos por que os christaãos hã rezõ de trautar menos bẽ os mouros do que faryã se isto nõ soubessem. [ZDM]

(125) Digo que he falso amigo porque se fose leal nõ lhe daria tal cõselho que he muyto danoso pera o corpo. [TC]

\footnotetext{
${ }^{9}$ O que poderá ser diacronicamente interpretado como persistência, no sentido em que este conceito é usado nos estudos de gramaticalização, ou seja, restrições de uso / valor de uma dada forma ou construção, num uso diacronicamente inovador (mais gramaticalizado) que decorrem da sua origem (mais lexical ou menos gramatical) (ver, e.o., Hopper \& Traugott 2003: 3; 121; Heine 2003: 589).

${ }^{10}$ Com esta designação uso, em termos genéricos, a noção proposta por Diewald (2006: 109) de «critical context[s]», apenas no sentido em que se remete com este conceito para contextos em que há ambiguidade (relacionada, nos casos de estudo que a autora apresenta, com opacidade morfossintática), tornando-se possíveis diferentes interpretações. A noção corresponde aproximadamente à de «bridging contexts» de Heine (2002: 84).
} 
Veja-se que num exemplo como (118) a interpretação é do mesmo tipo da que se gera em construções condicionais com MPS na prótase e na apódose, como as que se exemplificaram em (26) e (46), ou seja, nestes casos poder-se-á defender que os dois paradigmas estão, de facto, em competição. Há, neste exemplo, parece-me, de forma muito clara, uma contrafactual, com interpretação negativa da prótase ('não me conheceis'), e da apódose, nõ fallaryees assy, que pressupõe 'falastes assim'. Os restantes exemplos - (119), 122), (125) - permitem também o mesmo tipo de interpretação, ou seja, o tipo de interpretação que aparece, nos dados aqui analisados, mais geralmente associada a construções condicionais com MPS. Há assim, aparentemente, interferência de diferentes propriedades dos predicados da prótase e / ou apódose com verbos como saber, conhecer, achar, envolvendo também questões aspetuais, que permitem que o COND apareça já associado a leituras contrafactuais. ${ }^{11}$

Assinalei também um exemplo com MPS na prótase e COND na apódose (163), que aparentemente atesta a possibilidade de uma construção condicional em que formas dos dois paradigmas se combinam de modo diferente. A interpretação da construção parece ser ambígua, visto que o MPS na subordinada condicional anteciparia uma interpretação contrafactual, mas esse efeito é de algum modo anulado pelo COND da oração matriz, que parece antes induzir uma leitura hipotética:

(163) se a vos hũ tall lugar fora filhado em allgũa parte de vosso rregno, que mall vos poderia a vomtade mamter assossego ate que o tyrasseys de sugeição alhea. [ZPM]

No que respeita ainda a exemplos 'críticos', aqui em casos em que o COND aparece associado à marcação de interpretação contrafactual, assinalei os seguintes, com MPC do Conj na prótase:

(168) - Oo gemte cuytada, - dezia Gomçallo Vazquez - seria muito se vos nõ ouvesseys husado pellejas de mouros. Que espamto he este tam desarrazoado que vos toma? [ZPM]

(169) pois da bomdade de seu capitão eu teria bẽ que dezer $e$ vos que ouvir, se ho vos não tevesseys conheçido. [ZPM]

Poder-se-á admitir que, diacronicamente, estamos perante uma inovação, correspondente à emergência de desta forma composta do mais-que-perfeito do Conj na oração subordinada de construções condicionais, um contexto antes reservado ao MPS nas construções de interpretação contrafactual. Note-se ainda que, tal como acontece com outras formas verbais compostas em fases passadas da língua, se atesta aqui variação entre os auxiliares haver e ter (ouvesseys husado e tevesseys conheçido), sendo a ocorrência desta forma composta (haver / ter IMPConj + PP), aparentemente, ainda pouco expressiva, com duas únicas ocorrências no corpus, como antes referi.

Nos testemunhos que usei, atesta-se pontualmente (cf. Quadro 1), noutras ocorrências da construção em estudo, o uso do IMP em contextos em que de modo mais expressivo ocorre o COND. Assim, o IMP ocorre na matriz de construções com IMPConj na subordinada em (161) e (170) (neste caso na construção com haver de +INF), e também com MPS na subordinada (164), que atestam, hipoteticamente, também uma inovação formal, neste caso a 'substituição' do COND pelo IMP nestas construções:

(161) - Oo - disse aquelle cristão que estava ẽ auto de catyvo - como tu podias aproveitar a minha vida se quisesses. [ZPM]

\footnotetext{
${ }^{11}$ Veja-se Oliveira (2013: 527), que refere, a propósito do funcionamento do COND em português contemporâneo, que quando este ocorre com predicados eventivos torna possível ter uma leitura em que as situações venham a ocorrer, e com predicados estativos pode ter uma interpretação contrafactual.
} 
(170) E se foysse cousa cõuinhabel que alguũ ouuese dadiuinhar ou saber as cousas que hã de uiinr os mais nobres e os que fazem boa uida o auiam de ssaber asy como som os leterados e (...) e estes nõ no sabem. [TC]

(164) se o seu mestre salla nõ fora hy de presente que sua voõtade era de me matar. [Vesp]

Como se regista no Quadro 1, várias outras formas verbais se atestam nos testemunhos em construções condicionais, mas de forma quantitativamente pouco expressiva. Apresento apenas dois exemplos:

(166) por sete ou oito vezes estive tentado para me matar com peçonha (se Nosso Senhor me não fizera mercê de me ter na sua mão). [PPer]

(167) Quamto por matardes hũs poucos de mouros velhacos que aquy matastes sera comtado por pouco serviço de Deus a rrespeito de tam gramdes trabalhos $e$ despesas, caa, se mais nom ouvesse de ser, com quatro ou çimco mill dobras podereis [pudéreis] fazer maior serviço a Deus, ao menos em tirardes outros tamtos cristãos de poder dos ymfies. [ZPM]

Em (166), ocorre PPS na oração matriz e MPS na subordinada, num contexto discursivo específico, que aparentemente gera um implícito que corresponderia à apódose da condicional (parafraseável por 'e matarame'), pelo que em rigor a oração com PPS não corresponde à apódose da construção. Com o exemplo (167) pretendo apenas ilustrar um caso em que a forma do testemunho, podereis, pode corresponder a uma forma de FUT ('podereis') ou de MPS ('pudéreis'), não sendo possível neste contexto, a meu ver, optar por uma das interpretações.

\section{Conclusões}

Neste trabalho parti de uma recolha sistemática de dados de construções condicionais com a subordinada introduzida por se, em testemunhos textuais de finais do século XV a princípios do XVII. Verificando-se que nestas construções quer formas de COND quer formas de MPS ocorrem, alternativamente, na apódose, foi meu objetivo aferir se poderá considerar-se que as formas destes paradigmas competem no referido contexto.

A análise dos dados parece mostrar que a competição entre MPS e COND se limita, à partida, à sua ocorrência no mesmo tipo de construção, visto que, na larga maioria das ocorrências, há uma diferenciação na sua interpretação, diferenciação essa associada à persistência dos valores temporais (anterioridade / posterioridade em relação a um tempo passado) inerentes aos dois paradigmas. Assim, na maioria dos casos, só o COND admite uma leitura hipotética e o MPS uma leitura contrafactual.

Assinalei, porém, alguns exemplos 'críticos' cuja interpretação não se enquadra nesta diferenciação. Em parte das atestações, a inter-relação com outros valores marcados na construção - modalidade deôntica (com deuer), ambiguidade entre volição / intenção (com querer) - parece poder bloquear a leitura contrafactual do MPS, em certos contextos. Em contrapartida, outros contextos parecem poder permitir leituras contrafactuais do COND, com interferência de diferentes propriedades dos predicados da prótase e / ou apódose com saber, conhecer, achar, envolvendo também questões aspetuais. Estes vários fatores contextuais poderão ter contribuído para uma tendencial convergência ou 'atração' (De Smet et. al., 2018). Formula-se assim a hipótese, naturalmente a testar, com a análise de uma conjunto mais alargado de dados, no desenvolvimento da investigação, de que MPS e COND tenderiam a competir nas construções condicionais, com a possibilidade de ocorrência de ambas as formas com um mesmo tipo de (possível) interpretação, de que eventualmente viriam a decorrer leituras ambíguas.

Os dados levantados indiciam uma assinalável produtividade do MPS em construções condicionais, no período estudado (ainda que, como recorrentemente assinalei, os dados estritamente quantitativos devam ser 
aferidos contra outros parâmetros), o que contrasta, diacronicamente, com a obsolescência do MPS nestas construções (e noutros usos com valores modais). Coloca-se assim a questão de procurar identificar os fatores que virão a determinar essa obsolescência na história do português. Além da tendencial competição com o COND, que acima se colocou como hipótese, haverá também que considerar outros fatores que poderão ter tido relevância na sua substituição nos usos modais, não só pelo COND, na apódose de condicionais, mas ainda pelo IMPConj, na prótase das mesmas construções. Será de considerar também como possível fator associado ao desuso do MPS modal (em termos genéricos), a competição com formas compostas, paralelamente com o que ocorreu nos usos temporais do MPS. Estas, porém, não estão significativamente representadas no corpus, registando-se apenas duas de MPC do Conj (houvesse / tivesse + PP) na prótase (com COND na apódose) e nenhuma de COND composto (haveria / teria + PP) na apódose. Esta hipótese tem de ser enquadrada num conjunto mais alargado de fatores associados ao tendencial desuso do MPS, que afeta também os usos temporais, não tendo havido, porém, neste caso, obsolescência (total), apesar da emergência precoce do MPC (havia / tinha + PP). ${ }^{12}$

\section{Referências}

\section{Referências das edições das fontes e corpora}

[CRB] Lopes, David (1897) Chronica dos Reis de Bisnaga. Lisboa: IN (fonte CIPM).

[GSC] História da prouincia Sãcta Cruz que vulgarmete chamamos Brasil / feita por Pero Magalhäes de Gandauo. Em Lisboa: na officina de António Gonsaluez: vendense em casa de Ioão Lopez, 1576 (facsimile http://purl.pt/121; fonte Tycho Brahe).

[MSJ] Firmino, Jessica \& Cristina Sobral (2015) Memorial da Infanta Santa Joana. In Cristina Sobral et al. Corpus de Textos Antigos em português até 1525 (fonte CTA).

[PPer] Monteiro, Adolfo Casais (1983) Peregrinação de Fernão Mendes Pinto [transcrição de]. Lisboa: INCM (http://purl.pt/26737/3/\#/1; fonte Tycho Brahe).

[SBM] Melo, Gladstone Chaves de \& Aníbal Pinto de Castro (1984) Vida de D. Frei Bertolameu dos Mártires de Frei Luís de Sousa. Lisboa: IN-CM (fonte Tycho Brahe).

[TC] Machado, José Barbosa (2003) Tratado de Confissom - Edição Semidiplomática, Estudo Histórico e Linguístico. Braga: APPACDM (fonte CIPM).

[Vesp] Almeida, Maria Inês (2015) História de mui nobre Vespasiano. In Cristina Sobral et al. Corpus de Textos Antigos em português até 1525 (fonte CTA).

[ZDM] Fernandes, Adriano (2007) Crónica do Conde D. Duarte de Meneses de Gomes Eanes de Zurara. Estudo histórico-cultural e edição semidiplomática. Vol. II. Dissertação de Doutoramento, Universidade de Trás-os-Montes e Alto Douro.

[ZPM] Brocardo, Maria Teresa (1997) Crónica do Conde D. Pedro de Meneses de Gomes Eanes de Zurara. Edição e estudo. Lisboa: FCG / JNICT.

\section{CIPM - Corpus Informatizado do Português Medieval} http://clunl.fcsh.unl.pt/recursos-em-linha/corpus-informatizado-portugues-medieval-cipm

Corpus Histórico do Português Tycho Brahe http://www.tycho.iel.unicamp.br/corpus

CTA - Corpus de Textos Antigos em Português até 1525 http://alfclul.clul.ul.pt/teitok/cta/index.php?action=home

${ }^{12} \mathrm{E}$ era + PP, com verbos inacusativos, que formalmente continua a construção latina com o mesmo tipo de estrutura, com formas de ser (mas derivadas do verbo latino esse). 


\section{Outras referências}

Becker, Martin G. (2008) From temporal to modal: divergent fates of the Latin synthetic pluperfect in Spanish and Portuguese. In U. Detges \& R. Waltereit (eds.) The Paradox of Grammatical Change. Perspectives from Romance. Amsterdam: John Benjamins, pp. 147-180.

Berg, Thomas (2014) Competition as a unifying concept for the study of language. The Mental Lexicon 9, pp. 338-370

Brocardo, M. Teresa (2006a) «Haver» e «ter» em português medieval: Dados de textos dos séculos XIV e $\mathrm{XV}$, Revue de Linguistique Romane 70, pp. 95-122.

Brocardo, M. Teresa (2006b) Livro de Linhagens do Conde D. Pedro. Edição do fragmento manuscrito da Biblioteca da Ajuda (século XIV). Lisboa: IN-CM.

Brocardo, M. Teresa (2010) Portuguese pluperfect: elements for a diachronic approach. Estudos Linguísticos / Linguistic Studies 5, pp. 117-130.

Brocardo, M. Teresa (2012) O «passado do passado» - alguns dados para a história do pretérito mais-queperfeito em português. Verba Hispanica 20, pp. 33 - 48.

Brocardo, M. Teresa (2013) O pretérito perfeito - origem e evolução histórica. In Jasmina Markič \& Clara Nunes Correia (eds.) Descrições e Contrastes: Tópicos de gramática portuguesa com exemplos contrastivos eslovenos. Ljubljana: Univerzav Ljubljani, Filozofska fakulteta, pp. 111-117.

Brocardo, M. Teresa (2016) O futuro do passado /condicional - elementos para um estudo diacrónico. In Alvanira Lucia de Barros \& M. Teresa Brocardo (eds.) Estudos sobre o verbo em português: valores, marcas e construções: João Pessoa: Idéia, pp. 27-49.

Cunha, Celso \& Luís Filipe Lindley Cintra (1984) Nova Gramática do Português Contemporâneo. Lisboa: João Sá da Costa.

De Smet, Hendrik, Frauke D'hoedt, Lauren Fonteyn \& Kristel Van Goethem (2018) The changing functions of competing forms. Attraction and differentiation. Cognitive Linguistics: an interdisciplinary journal of cognitive science 29. http://hdl.handle.net/2078.1/189545.

Diewald, Gabriele (2006) Context types in grammaticalization as constructions. Constructions SV1-9/2006. www.constructions-online.de, urn:nbn:de:0009-4-6860.

Ferreira, José de Azevedo (1980) Alphonse X. Primeyra Partida. Edition et Etude. Braga: INIC.

Ferreira, José de Azevedo (1987) Afonso X. Foro Real. Edição. Estudo Linguístico e Glossário, 2 vols. Lisboa: INIC.

Heine, Bernd (2002) On the role of context in grammaticalization. In Ilse Wischer \& Gabriele Diewald (eds.) New Reflections on Grammaticalization. Amsterdam / Philadelphia: John Benjamins, pp. 83-101.

Heine, Bernd (2003) Grammaticalization. In Brian Joseph \& Richard D. Janda (eds.) The Handbook of Historical Linguistics. Cambridge USA / Oxford UK: Blackwell, pp. 575-601.

Hopper, Paul J. \& Elizabeth Closs Traugott $\left(2003^{2}\right)$ Grammaticalization. Cambridge: Cambridge University Press.

Mattos e Silva, Rosa Virgínia (1989) Estruturas trecentistas. Elementos para uma gramática do Português Arcaico. Lisboa: IN-CM.

Mattos e Silva, Rosa Virgínia (2002) Vitórias de «ter» sobre «haver» nos meados do século XVI: usos e teoria em João de Barros. In Rosa Virgínia Mattos e Silva \& Américo Venâncio Lopes Machado Filho (eds.) $O$ Português Quinhentista: Estudos Lingüísticos. Salvador/Feira de Santana: EDUFBA/UEFS, pp. 119-142.

Oliveira, Fátima (2013) Tempo verbal. In Eduardo Paiva Raposo et al. Gramática do Português, Vol. I. Lisboa: Fundação Calouste Gulbenkian, pp. 509-553.

Parkinson, Jennie K. (2009) A diachronic study into the distributions of two Italo-Romance synthetic conditional forms, $\mathrm{PhD}$ Thesis, University of St. Andrews. http://hdl.handle.net/10023/737.

Pinkster, Harm (1995) Sintaxis y semántica del latin. Madrid: Ediciones Clásicas. 
Maria Teresa Brocardo

Said Ali, Manuel (19646) Gramática Histórica da Língua Portuguesa. São Paulo: Melhoramentos.

Salvi, Giampaolo (2011) Morphosyntactic Persistence. In Martin Maiden, John Charles Smith \& Adam Ledgeway (eds.) The Cambridge History of the Romance Languages, Vol. I Structures. Cambridge: Cambridge University Press, pp. 318-380. 